\title{
Editorial
}

\section{Recent Advances in Small-Angle Neutron Scattering}

\author{
Sebastian Jaksch (1)
}

Jülich Centre for Neutron Science JCNS at Heinz Maier-Leibnitz Zentrum (MLZ),

Forschungszentrum Jülich GmbH, Lichtenbergstr. 1, 85748 Garching, Germany; s.jaksch@fz-juelich.de

Citation: Jaksch, S. Recent Advances in Small-Angle Neutron Scattering. Appl. Sci. 2022, 12, 90. https:// doi.org/10.3390/app12010090

Received: 15 December 2021

Accepted: 17 December 2021

Published: 22 December 2021

Publisher's Note: MDPI stays neutral with regard to jurisdictional claims in published maps and institutional affiliations.

Copyright: (ㄷ 2021 by the author. Licensee MDPI, Basel, Switzerland. This article is an open access article distributed under the terms and conditions of the Creative Commons Attribution (CC BY) license (https:// creativecommons.org/licenses/by/ $4.0 /)$.
Small-angle scattering, and its neutron expression small-angle neutron scattering (SANS), has developed into an invaluable tool for the investigation of microscopic and mesoscopic structures in recent decades. This Special Issue aims to provide an overview of the recent experimental and technological advances of this technique. The knowledge of advances in SANS, being ubiquitous in physical sciences, therefore promises to help a wide range of researchers in their respective fields, whether that is physical chemistry, biophysics, pharmaceutic and medical studies or the studies of magnetic phenomena.

This overview comprises the description of new instrumentation, sample environments and instrument control and data handling, over new experimental applications and their combination with complementary experimental techniques.

The instrumentation descriptions deliver an in-depth understanding of the status of the technical capabilities of SANS in current instrumentation as well as the sample environment. With this knowledge, experimenters can now better gauge the technical feasibility of their experiments, which is both important for young researchers who are new to the field, but also to more experienced researchers who may want to revisit experiments which were not feasible at an earlier point in time. Both approaches promise new scientific insights and allow using SANS to capacity. Additionally, scientists at facilities which provide SANS instruments may use some of the possibilities shown for sample environments to widen their experimental range.

In "Technical Specification of the Small-Angle Neutron Scattering Instrument SKADI at the European Spallation Source (ESS)" [1], the capacity and capability of a state-of-the-art SANS instrument is presented, which is currently constructed at the ESS. Some of the features described are not fundamentally based on the higher brilliance of the source as such, so those can in principle also be realized at existing facilities.

Closely linked to that are three papers on flexible sample environments at the ESS [2-4]. While they are based on the technical concept of SKADI, the ideas should be universally applicable and support original ideas by other researchers.

Two other papers are primarily linked to the facilities of the Oak Ridge National Laboratory (ORNL), and give a review of the soft matter sample environments for SANS available there [5] and present the newest instrumental control system [6]. While this is particularly important to potential users of the ORNL facilities, those ideas can again be used as inspiration.

The last technical paper in this issue focuses on the impact of SANS background in the case of grazing incidence SANS (GISANS) [7]. GISANS has been developed into a method in its own right over the last decades; however, it still remains closely linked to SANS, both scientifically and technologically. Considering the mutual impacts and differences allows for a more complete understanding of the measured data.

The same is true for the description of complementary techniques. Additionally, here, inspiration for new experiments both on new and already otherwise-investigated samples can be taken from the manuscripts published in this issue.

Showing two complementary in situ techniques for SANS "Light Scattering and Absorption Complementarities to Neutron Scattering: In Situ FTIR and DLS Techniques at the High-Intensity and Extended Q-Range SANS Diffractometer KWS-2" [8] describes a 
setup where two methods are combined with SANS, both of which deliver data which are otherwise unobtainable in SANS yet help with a comprehensive data evaluation.

The description of simultaneous SANS and small-angle X-ray scattering (SAXS) in "Simultaneous SAXS SANS Method at D22 of ILL Instrument Upgrade" [9] shows an additional example of complementary measurements and the achievable benefits of simultaneous in situ measurements. Even though both methods are small-angle scattering and thus governed by similar principles, the combination of two independent contrast systems can illuminate features which would otherwise be hidden, especially in the case of soft matter, where the contrast differences for hydrogenated and deuterated samples are very pronounced.

As a final, but important, component of this issue, new ingenious experiments and their evaluations are featured. Those state-of-the-art applications of the SANS technology may likewise broaden the view of SANS usage for new experiments.

In "Feasibility of Probing the Filler Restructuring in Magnetoactive Elastomers by Ultra-Small-Angle Neutron Scattering" [10], SANS as a method to investigate material properties on the micrometer scale in bulk is described. Here, future research approaches for such systems, such as polarized neutron scattering and scattering at low temperatures, are also discussed.

While the manuscript "The Analysis of Periodic Order in Monolayers of Colloidal Superballs" [11] strictly only uses SAXS data, the method applied for the analysis is fully applicable for SANS experiments. Since such systems attract the interest of a large community and also show a high degree of technical applicability, this analytical method is also of interest for researchers focused on SANS measurements.

While for such a wide field as SANS there cannot be any claim for completeness, this Special Issue is a good representation of the technologies available, newly developed and newly applied in the field of SANS. With each article giving an in-depth description of the particular described feature, technique or approach, it can be hoped the articles collected in this issue may help the readers to conceive both new and improved ideas about the application of the SANS technique in their respective fields.

Funding: This research received no external funding.

Institutional Review Board Statement: Not applicable.

Informed Consent Statement: Not applicable.

Data Availability Statement: Not applicable.

Conflicts of Interest: The authors declare no conflict of interest.

\section{References}

1. Jaksch, S.; Chennevière, A.; Désert, S.; Kozielewski, T.; Feilbach, H.; Lavie, P.; Hanslik, R.; Gussen, A.; Butterweck, S.; Engels, R.; et al. Technical Specification of the Small-Angle Neutron Scattering Instrument SKADI at the European Spallation Source. Appl. Sci. 2021, 11, 3620. [CrossRef]

2. Kühnhammer, M.; Widmann, T.; Kreuzer, L.P.; Schmid, A.J.; Wiehemeier, L.; Frielinghaus, H.; Jaksch, S.; Bögershausen, T.; Barron, P.; Schneider, H.; et al. Flexible Sample Environments for the Investigation of Soft Matter at the European Spallation Source: Part III-The Macroscopic Foam Cell. Appl. Sci. 2021, 11, 5116. [CrossRef]

3. Schmid, A.J.; Wiehemeier, L.; Jaksch, S.; Schneider, H.; Hiess, A.; Bögershausen, T.; Widmann, T.; Reitenbach, J.; Kreuzer, L.P.; Kühnhammer, M.; et al. Flexible Sample Environments for the Investigation of Soft Matter at the European Spallation Source: Part I-The In Situ SANS/DLS Setup. Appl. Sci. 2021, 11, 4089. [CrossRef]

4. Widmann, T.; Kreuzer, L.P.; Kühnhammer, M.; Schmid, A.J.; Wiehemeier, L.; Jaksch, S.; Frielinghaus, H.; Löhmann, O.; Schneider, H.; Hiess, A.; et al. Flexible Sample Environment for the Investigation of Soft Matter at the European Spallation Source: Part II-The GISANS Setup. Appl. Sci. 2021, 11, 4036. [CrossRef]

5. Urban, V.S.; Heller, W.T.; Katsaras, J.; Bras, W. Soft Matter Sample Environments for Time-Resolved Small Angle Neutron Scattering Experiments: A Review. Appl. Sci. 2021, 11, 5566. [CrossRef]

6. Yao, X.; Avery, B.; Bobrek, M.; Debeer-Schmitt, L.; Geng, X.; Gregory, R.; Guyotte, G.; Harrington, M.; Hartman, S.; He, L.; et al. A Unified User-Friendly Instrument Control and Data Acquisition System for the ORNL SANS Instrument Suite. Appl. Sci. 2021, 11, 1216. [CrossRef] 
7. Kyrey, T.; Ganeva, M.; Witte, J.; Feoktystov, A.; Wellert, S.; Holderer, O. Grazing Incidence Small-Angle Neutron Scattering: Background Determination and Optimization for Soft Matter Samples. Appl. Sci. 2021, 11, 3085. [CrossRef]

8. Balacescu, L.; Brandl, G.; Kaneko, F.; Schrader, T.E.; Radulescu, A. Light Scattering and Absorption Complementarities to Neutron Scattering: In Situ FTIR and DLS Techniques at the High-Intensity and Extended Q-Range SANS Diffractometer KWS-2. Appl. Sci. 2021, 11, 5135. [CrossRef]

9. Metwalli, E.; Götz, K.; Zech, T.; Bär, C.; Schuldes, I.; Martel, A.; Porcar, L.; Unruh, T. Simultaneous SAXS/SANS Method at D22 of ILL: Instrument Upgrade. Appl. Sci. 2021, 11, 5925. [CrossRef]

10. Belyaeva, I.A.; Klepp, J.; Lemmel, H.; Shamonin, M. Feasibility of Probing the Filler Restructuring in Magnetoactive Elastomers by Ultra-Small-Angle Neutron Scattering. Appl. Sci. 2021, 11, 4470. [CrossRef]

11. Napel, D.N.T.; Meijer, J.-M.; Petukhov, A.V. The Analysis of Periodic Order in Monolayers of Colloidal Superballs. Appl. Sci. 2021, 11, 5117. [CrossRef] 